This item was submitted to Loughborough's Research Repository by the author.

Items in Figshare are protected by copyright, with all rights reserved, unless otherwise indicated.

\title{
Modelling the exhaust gas recirculation mass flow rate in modern diesel engines
}

PLEASE CITE THE PUBLISHED VERSION

http://dx.doi.org/10.4271/2016-01-0550

PUBLISHER

(C) SAE International

VERSION

VoR (Version of Record)

LICENCE

CC BY-NC-ND 4.0

\section{REPOSITORY RECORD}

Yang, Zhijia, Edward Winward, Gary O'Brien, Richard Stobart, and Dezong Zhao. 2017. "Modelling the Exhaust Gas Recirculation Mass Flow Rate in Modern Diesel Engines". figshare.

https://hdl.handle.net/2134/24353. 


\section{Modelling the Exhaust Gas Recirculation Mass Flow Rate in Modern Diesel Engines}

\section{Zhijia Yang and Edward Winward}

Loughborough Univ.

\section{Gary O'Brien}

HORIBA UK Limited

\section{Richard Stobart and Dezong Zhao \\ Loughborough Univ.}

CITATION: Yang, Z., Winward, E., O'Brien, G., Stobart, R. et al., "Modelling the Exhaust Gas Recirculation Mass Flow Rate in Modern Diesel Engines," SAE Technical Paper 2016-01-0550, 2016, doi:10.4271/2016-01-0550.

Copyright (C) 2016 SAE International

\begin{abstract}
The intrinsic model accuracy limit of a commonly used Exhaust Gas Recirculation (EGR) mass flow rate model in diesel engine air path control is discussed in this paper. This EGR mass flow rate model is based on the flow of a compressible ideal gas with unchanged specific heat ratio through a restriction cross-area within a duct. A practical identification procedure of the model parameters is proposed based on the analysis of the engine data and model structure. This procedure has several advantages which include simplicity, low computation burden and low engine test cost. It is shown that model tuning requires only an EGR valve sweep test at a few engine steady state operating points. It is also shown that good model accuracy can be achieved when the control variables of other air path devices, e.g. the vane position of a Variable Geometry Turbocharger (VGT) and the torque demand of an Electric Turbo Assist (ETA), are kept constant during the EGR valve sweep test used to tune the model. Two different diesel engines are used in this work to demonstrate the model tuning procedure and the model validation results. Both engines are equipped with a high pressure external EGR system and a VGT. One of the engines has a relatively new air system device - an ETA. The model validation results of both engines show good model accuracy not only at steady state engine operating points but also during engine transients.
\end{abstract}

\section{Introduction}

In order to improve the engine performance and reduce engine emissions, modern diesel engines are usually equipped with various types of device in the air path system such as Low Pressure (LP) and High Pressure (HP) Exhaust Gas Recirculation (EGR), Variable Geometry Turbocharger (VGT), and more recently two-stage or twin-stage turbocharger, Electric Turbo Compound (ETC) or Electric Turbo Assist (ETA) etc. $[\underline{1}, \underline{2}, \underline{3}, \underline{4}, \underline{5}, \underline{6}]$. Closed-loop control is a good solution to precisely use these air path devices for optimizing engine performance and minimizing emissions and fuel consumptions $[\underline{7}, \underline{8}]$. In such closed-loop air path control systems, the controlled variables could be intake manifold pressure, intake fresh air flow rate, EGR flow rate, exhaust pressure etc. Apart from the EGR flow rate, the other variables are already available in most production diesel engines. In the test cell, EGR flow rate can be estimated from EGR ratio which is measured using an emissions analyzer. Alternatively, there are commercial gas flow rate measurement devices such as Pitot, Coriolis, Venturi, and Orifice type flow meters that can be used to measure the EGR flow rate in the test cell [9]. However it is necessary to modify the EGR path to integrate these flow meters and this in turn can change the flow characteristics. Another consideration is the influence of engine exhaust gas pulsation on the flow measurement, this can require a compensation algorithm to filter out the influence of the exhaust gas pulsation to achieve a reliable flow measurement for some measurement devices $[\underline{10}, \underline{11}, \underline{12}]$. The authors' have found from experimental experience with a Venturi flow meter on a diesel engine EGR path, that the pressure pulsation in the exhaust manifold combined with the unidirectional flow rate measurement of a Venturi flow meter, present a challenge for achieving a reliable and robust EGR flow measurement.

There are a number of works in literature that discuss EGR flow rate measurement. The EGR flow rate can be estimated from $\mathrm{CO} 2$ concentration in the intake manifold by measuring the infrared radiation absorption amount of the $\mathrm{CO} 2[\underline{13}, \underline{14}]$. A thermal anemometer which uses a ceramic element can be made into an EGR flow rate sensor [15]. It is also reported that the hot EGR mass fraction can be estimated by the temperature of hot EGR gas and fresh charging air using the thermal balance method $[16,17]$. In literature the majority of reported research concerning EGR system (e.g. air path control, model based misfire detection) use the orifice type flow rate model that is applied on the EGR valve element $[\underline{18}$, $\underline{19}, \underline{20}, \underline{21}, \underline{22}, \underline{23}]$. It is claimed in [24] that it is also possible to estimate the EGR flow rate by applying orifice type flow rate model 
on the EGR cooler element. This type of EGR flow rate model is also a very important part of Mean Valve Engine Model (MVEM) which is the foundation for fast engine simulation and online optimization $[\underline{25}, \underline{26}, \underline{27}]$.

There are two types of orifice flow rate model that are found in the EGR flow rate modelling literature. The first one is based on the assumption of isothermal conditions of a compressible ideal gas $[\underline{7}, \underline{18}, \underline{19}, \underline{20}, \underline{21}, \underline{22}]$, the other is based on the assumption of incompressible feature of an ideal gas $[\underline{23}, \underline{24}]$. The later has a more simple form than the first one. However, most of the orifice based EGR flow rate model investigations use the first one since it has better accuracy and it is this model which is used in this study. In addition to the EGR valve open position, there are three other inputs to this model: 1). the upstream pressure 2). the upstream temperature and 3). the downstream pressure. Intake manifold pressure is the logical choice for the downstream pressure. Most modeling work found in the literature uses exhaust pressure and exhaust temperature respectively as the upstream pressure and temperature inputs to the model $[\underline{2}, \underline{3}, \underline{7}, \underline{21}, \underline{22}, \underline{25}, \underline{26}, \underline{28}]$. If the exhaust pressure and exhaust temperature are not available, a black box model can be developed to provide these variables into the EGR flow rate model [28]. It is reported in [23] that the pressure and temperature of the EGR gas at the exit of EGR cooler can be used as the upstream pressure and temperature respectively. An example of the use of the exhaust pressure and the temperature of the EGR gas at the exit of the EGR cooler can be found in [18]. In this paper it is shown that greater model accuracy is achieved with EGR cooler exit temperature.

A brief description of the tuning method of the EGR flow rate model used in this work is described in [25] and this proposes a detailed practical model tuning procedure i.e. identification method for the EGR flow rate model parameters. In this paper a simplified process is demonstrated for the tuning of the parameters of the EGR flow rate model that is explored.

The majority of the EGR flow rate modelling examples seen in the literature focus on high pressure EGR together with VGT. The application of the EGR model on dual-loop EGR system could be found in [] $]$. The operation of the EGR flow rate model was proved to work in an air system consisting of a higher pressure EGR system and a twin-stage turbocharger [ $\underline{3}$ ]. However, to the best of the authors' knowledge, this is the first reported work which presents a validation of the EGR flow rate model used in this work on an air system with three elements which include: high pressure EGR, VGT and ETA.

The paper is organized as follows. Section 2 describes the experimental setup of the two engines referred to in this study. The first part of Section 3 presents a step-by-step formation of the orifice based EGR flow rate model. In the second part of Section 3 , a practical model tuning procedure is presented and demonstrated with its application on the first engine which has high pressure EGR and VGT. Section 4 presents modelling and valuation results for the second engine operating transiently, this engine is equipped with high pressure EGR, VGT and an ETA. Finally, the summary and conclusions are given in Section 5.

\section{Experimental Setup}

The experimental work presented in this study was undertaken at the Loughborough University Powertrain Laboratory, UK.

\section{System 1: Cat C6.6 Engine}

The first engine used in this study is a Cat C6.6 $®$ ACERT ${ }^{\mathrm{TM}}$ heavly-duty off-highway diesel engine. The engine is a six cylinder, 6.6 liter engine equipped with a common rail fuel system. This engine has been modified with a prototype HP EGR system together with an EGR cooler and a single-stage VGT equipped turbocharger. The EGR system has dual EGR valves in parallel. The two valves are synchronized to open and close by way of a single control input signal. This configuration enables a higher EGR flow rate compared to a single EGR valve. Engine maximum power is $159 \mathrm{~kW}$ with peak torque of $920 \mathrm{Nm}$ at $1400 \mathrm{rpm}$. Engine maximum speed is $2200 \mathrm{rpm}$.

This engine was installed in a test bed with a Froude AG400-HS eddy current Dynamometer controlled by a CP Engineering Cadet V14 dynamometer control system. Figure 1 and Figure 2 show the test cell and the control desk respectively. The original production Engine Control Module (ECM) was removed and replaced by two separate air path and fuel path control systems. A MathWorks xPC Target ${ }^{\mathrm{TM}}$ based control system has been developed to control both boost pressure and EGR rate. The $\mathrm{xPC}$ is a high performance desk-PC which enables Simulink ${ }^{\circledR}$ and Stateflow ${ }^{\circledR}$ models to be executed in real time on PC-compatible hardware. A multi-shot fuel path control system has been developed using a National Instruments ${ }^{\text {TM }}$ (NI) PXI Real Time (RT) platform together with Field-Programmable Gate Array (FPGA) and Drivven Diesel Injector Driver Modules (DI Drivers). A host PC is used to program in LabVIEW and download the code to PXI RT. A detailed description of this engine control system can be found in [29].

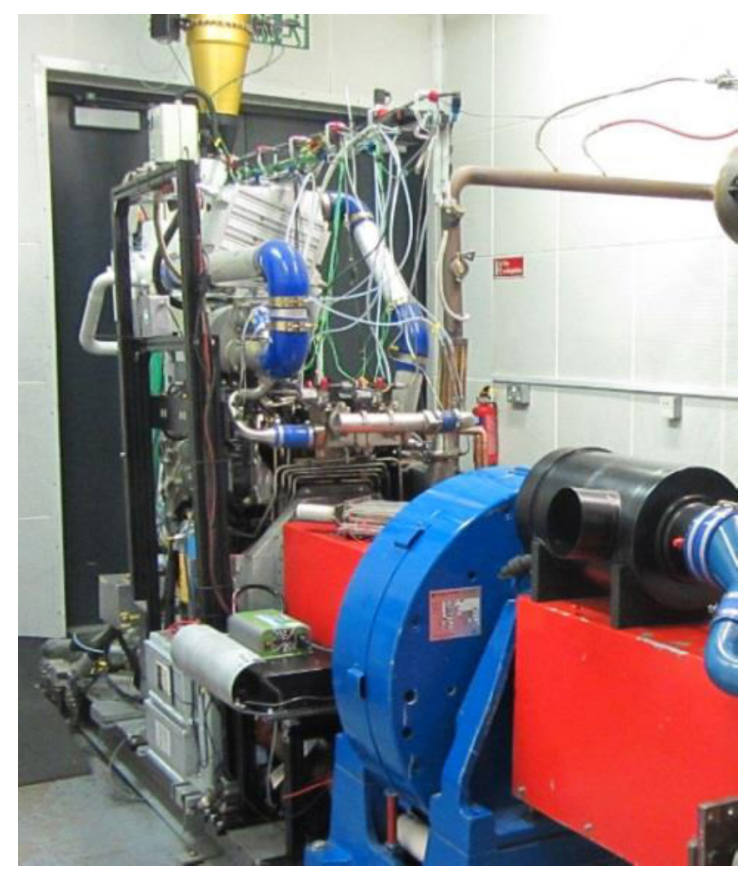

Figure 1. C6.6 engine in the test cell 


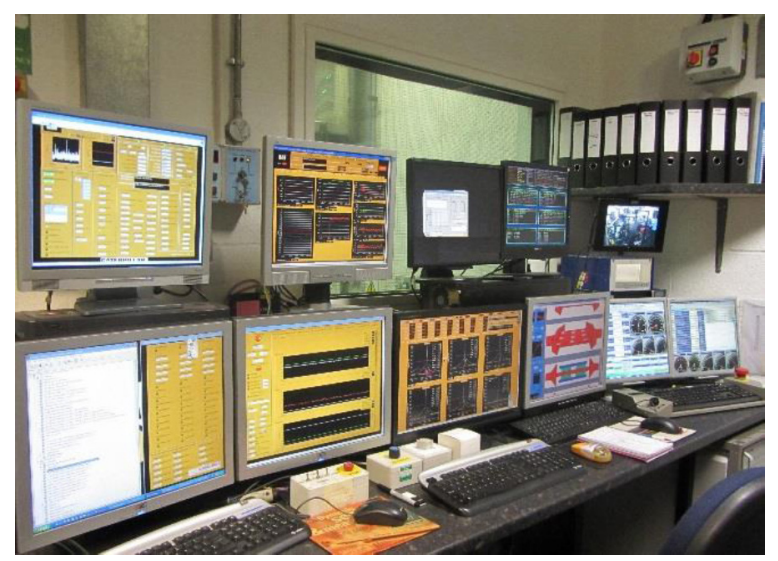

Figure 2. C6.6 engine control room set-up

All six cylinders' combustion pressure can be obtained by six Kistler 6125B ThermoCOMP® Quartz pressure sensors. Engine crank position tracking is performed using a Hengstler optical encoder with a resolution of one Crank Angle Degree (CAD). The injector current of the six injectors and also the six cylinder pressure signals are monitored and can be used in advanced closed loop control, Figure 3. For both engines in this work, the measured EGR flow rate was computed from the percentage EGR measured with a Horiba Mexa 9100-DEGR emissions analyzer.

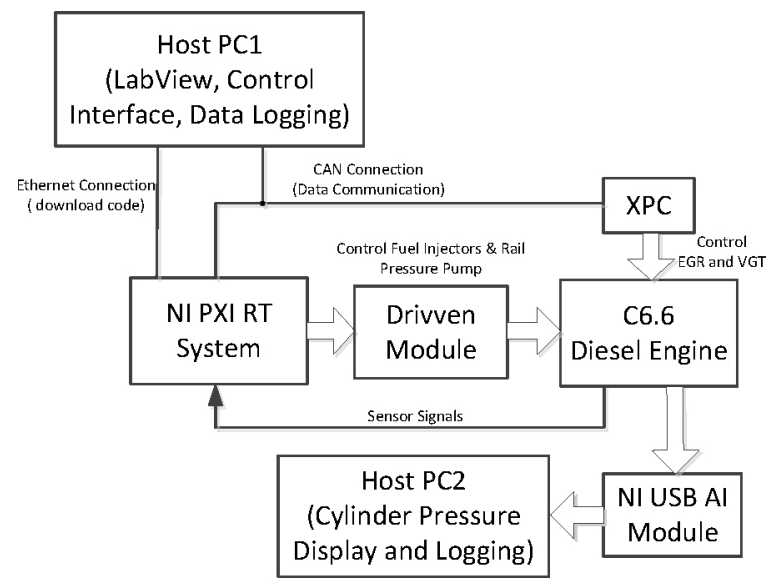

Figure 3(a). Diagram of C6.6 Engine Control System

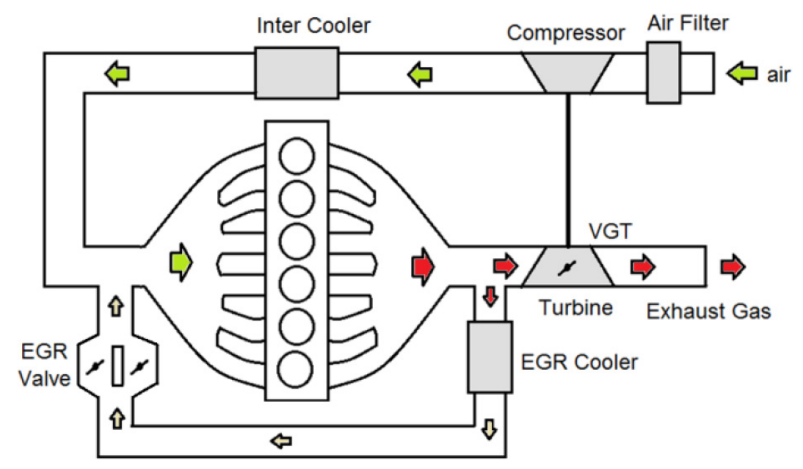

Figure 3(b). Schematice Layout of C6.6 Engine Air System

\section{System 2: Cat C7.1 Engine}

The second example engine used in this study is a Cat C7.1 ${ }^{\circledR}$

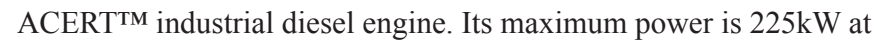
2200rpm. It is equipped with a common rail fuel system, HP EGR system and EGR cooler. This EGR system has a single EGR valve.
One of the key differences between this engine and the C6.6 diesel engine, is that the C7.1 engine has been modified to be equipped with a BorgWarner BV63 VGT turbocharger that has been specially adapted to have a Switched Reluctance electric machine installed between the turbine and the compressor [31, 32]. The SR electrical machine can augment the turbine power through electric motoring and can also absorb energy through electric regeneration (i.e. braking of the turbocharger). The introduction of the ETA motor adds an extra degree of freedom to the engine air path system in addition to EGR valve positon and VGT vane position.

The command signal sent to the ETA is equivalent to the motor torque percentage and is sent via a CAN connection from an XPC. The ETA provides rapid boost during engine acceleration and energy recovery during engine deceleration. One way to use these three air path components is to develop a Three-Input-Three-Output (3I3O) multivariable control system and an accurate EGR flow rate model is crucial in developing this form of control system.

The C7.1 engine is installed in a test cell with an AVL $480 \mathrm{~kW}$ DynoDur Dynamometer controlled by an AVL Bobcat test bed automation system. Figure 4 shows the C7.1 engine in the test cell together with a Horiba Mexa 9100-DEGR emissions analyzer used in this study. Figure 5 shows the control room set-up.

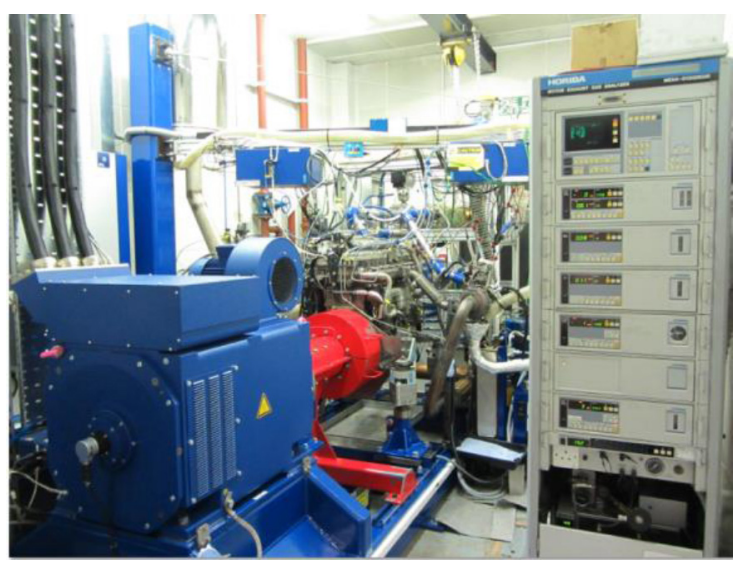

Figure 4. C7.1 engine in the test cell

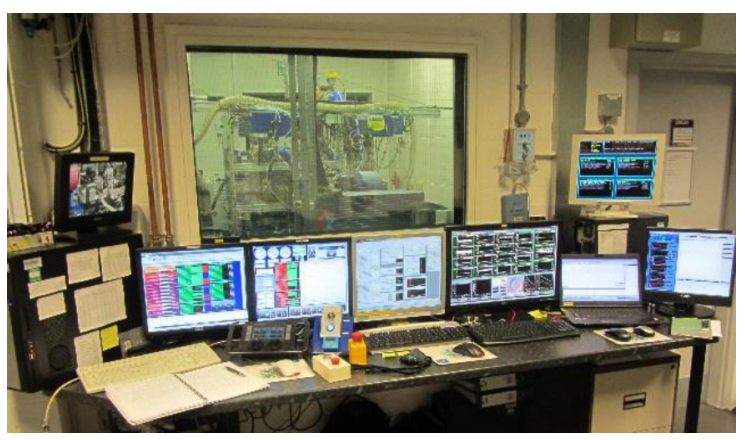

Figure 5. C7.1 engine control room set-up

The control system of the C7.1 engine is different to that of C6.6 engine, Figure 6. An xPC is used to interface with the ECM via CAN communication to change ECM control function. A second CAN connection from the $\mathrm{xPC}$ is used to control the ETA device. The EGR flow rate model and air path controller is programmed in a Simulink 
model which is then compiled to execute on the xPC. The test data was recorded on the xPC. The EGR model tuning work was carried out off line.

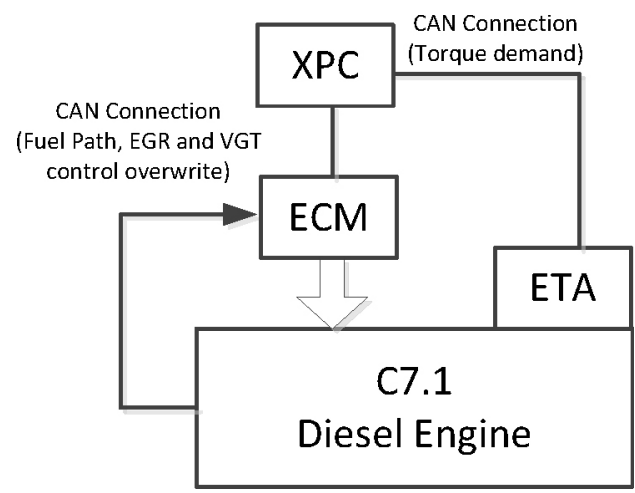

Figure 6(a). Diagram of Control System of C7.1 Engine in Test Cell

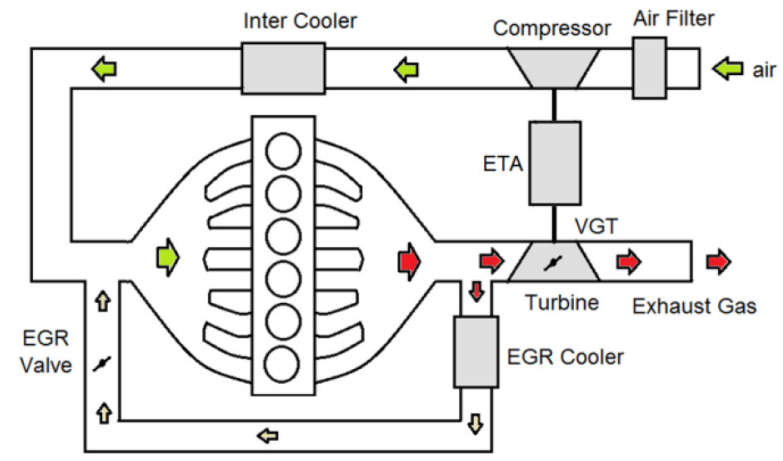

Figure 6(b). Schematice Layout of C7.1 Engine Air System

\section{Modelling EGR Mass Flow Rate}

The motivation for modelling EGR flow rate in this paper is the online EGR flow rate estimation for engine air path control and Thermoelectric Generator (TEG) Component-In-Loop (CIL) engine tests. The requirements for the EGR flow rate model are therefore: good model accuracy, low computational resource utilization and fast model tuning. The following two subsections demonstrate an orifice type EGR mass flow rate model which could meet these requirements. This model is based on the assumption of isentropic process conditions of a compressible ideal gas.

\section{EGR Flow Rate Model}

The orifice type EGR mass flow rate model that is discussed in this paper is based on physical equations for an ideal gas flow through a restriction area within a duct [이 $]$ under some ideal condition assumptions. These assumptions include large upstream and downstream reservoirs where the gas is in stagnation conditions; the impact of EGR cooler on the EGR flow rate is ignored; the EGR flow is a steady adiabatic reversible (frictionless) flow; the EGR flow path is a straight duct that has the same diameter along the EGR flow path except at the EGR valve location where the flow area can be varied by adjusting the valve position.

Figure 7 shows the ideal conditions and variables used in EGR flow model and their respective locations for EGR gas flow through a restriction area. $p_{1}, T_{1}$ are the stagnation pressure and temperature at the upstream reservoir respectively. $p_{2}, T_{2}$ are the stagnation pressure and temperature at the downstream reservoir respectively. The EGR gas has zero flow velocity at both the upstream and downstream reservoirs. The cross-sectional area of the duct and of the restriction area (throat) is $A_{R}$ and $A_{T}$ respectively. The EGR gas pressure will drop abruptly at the throat position. The minimum pressure at the throat is $p_{T}$. At the same location of the minimum throat pressure, the EGR gas temperature and flow velocity are defined as $T_{T}$ and $V_{T}$ respectively. $p_{0}$ and $T_{0}$ are the stagnation pressure and temperature at the throat location respectively.

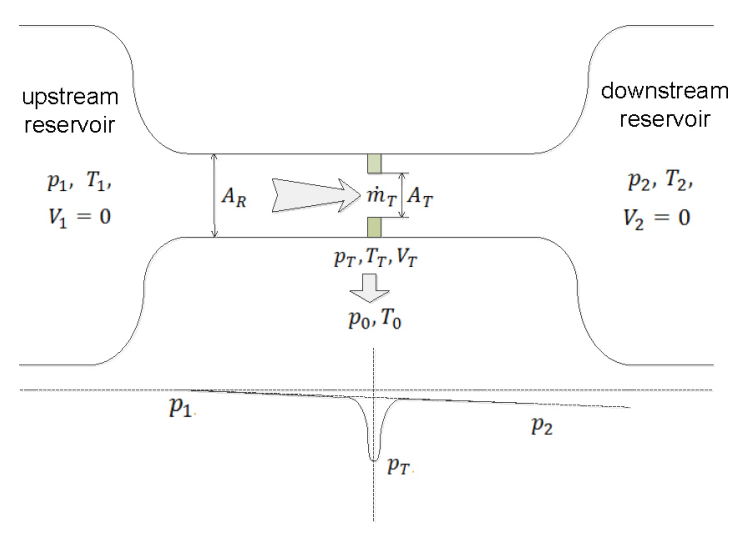

Figure 7. Ideal EGR gas flow through a restriction area

The stagnation temperature $T_{0}$ can be computed using steady flow energy equation (1) [이]:

$$
T_{0}=T_{T}+\frac{V_{T}^{2}}{2 c_{p}}
$$

where, $c_{p}$ is the heat capacity of EGR gas at constant pressure. Substituting the flow velocity $V_{T}$ with Mach Number $M$, the ratio of stagnation temperature and real gas temperature is:

$$
\frac{T_{0}}{T_{T}}=1+\frac{\gamma-1}{2} M_{T}^{2}
$$

The Mach number at the throat is defined as:

$$
M_{T}=\frac{V_{T}}{\sqrt{\gamma R T_{T}}}
$$

where, $\gamma$ is the specific heat ratio, $R$ is the specific ideal gas constant. The isentropic relation between the ratio of real temperature to stagnation temperature and the ratio of real pressure to stagnation pressure gives:

$$
\frac{T_{T}}{T_{0}}=\left(\frac{p_{T}}{p_{0}}\right)^{\frac{\gamma-1}{\gamma}}
$$

Combining equation (2) and equation (4) together, the pressure ratio of stagnation pressure to real pressure can be re-formulated to a function of the specific heat ratio $\gamma$ and the Mach Number $M$ : 


$$
\frac{p_{0}}{p_{T}}=\left(1+\frac{\gamma-1}{2} M_{T}^{2}\right)^{\frac{\gamma}{\gamma-1}}
$$

The mass flow rate at the throat is defined as:

$$
\dot{m}_{T}=\rho_{T} A_{T} V_{T}
$$

where, $\rho_{T}$ is the gas density at the throat location and could be estimated using:

$$
\rho_{T}=\frac{p_{T}}{R T_{T}}
$$

Equation (6) can be rearranged into the following equation using equation (3), (ㅁ) and ()):

$$
\dot{m}_{T}=\frac{A_{T} p_{0}}{\sqrt{R T_{0}}} \phi\left(\gamma, \frac{p_{T}}{p_{0}}\right)
$$

where $\phi$ is a function of $\gamma$ and pressure ratio $\frac{p_{T}}{p_{0}}$ and can be seen as a pressure ratio characteristic function in EGR flow rate model and is given by:

$$
\phi\left(\gamma, \frac{p_{T}}{p_{0}}\right)=\left(\frac{p_{T}}{p_{0}}\right)^{\frac{1}{\gamma}} \sqrt{\frac{2 \gamma}{\gamma-1}\left[1-\left(\frac{p_{T}}{p_{0}}\right)^{\frac{\gamma-1}{\gamma}}\right]}
$$

Because there is an upper limit of flow velocity at the throat which is the velocity of sound, then the equation (5) will give the minimum value of the ratio of real pressure to stagnation pressure at the throat location which is:

$$
\left(\frac{p_{T}}{p_{0}}\right)_{\min }=\left(\frac{2}{\gamma+1}\right)^{\frac{\gamma}{\gamma-1}}
$$

The flow rate is saturated at $\left(\frac{p_{T}}{p_{0}}\right)_{\min }$ which means that when the pressure ratio is smaller than the minimum value, the gas flow rate does not increase. Obviously the upper limit of the pressure ratio $\frac{p_{T}}{p_{0}}$ is 1 when there is no flow at the throat.

The value of $\phi$ against pressure ratio $\frac{p_{T}}{p_{0}}$, (the pressure ratio characteristic curve in EGR flow rate model) and the minimum pressure ratio $\left(\frac{p_{T}}{p_{0}}\right)_{\min }$ are shown in Figure 8 for three example cases for which $\gamma$ has a value of $1.3,1.35$ and 1.4 respectively.

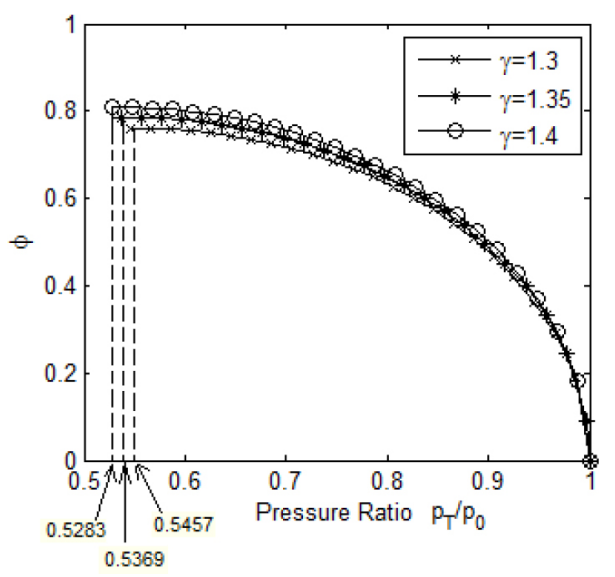

Figure 8. Pressure ratio characteristic curves for three specific heat ratio cases (the values after the arrows are minimum pressure ratio value for three specific heat ratio cases)

It can be seen from Figure 8 that the specific heat ratio $\gamma$ has a small impact on the minimum pressure ratio and the pressure ratio characteristic function $\phi$. Consequently $\phi$ can be simplified as a function of only one input variable, the pressure ratio $\frac{p_{T}}{p_{0}}$. Therefore, equation (8) can be rewritten as:

$$
\dot{m}_{T}=\frac{A_{T} p_{0}}{\sqrt{R T_{0}}} \phi\left(\frac{p_{T}}{p_{0}}\right), \quad\left(\frac{p_{T}}{p_{0}}\right)_{\min }<\frac{p_{T}}{p_{0}}<1
$$

However, in reality, the pressure at the throat location $p_{T}$ is not available. The commonly used alternative variable is the intake manifold pressure which in this paper has the symbol name $p_{2}$. This replacement will unavoidably result in the reduction of model accuracy. As the flow velocity at the throat is also unknown, the stagnation temperature $T_{0}$ and stagnation pressure $p_{0}$ are both unknown variables. However, the ideal condition assumption of an upstream reservoir suggests that $p_{1}$ and $T_{1}$ can be used to replace $p_{0}$ and $T_{0}$ in equation (8).

For an engine, the exhaust pressure and exhaust temperature are taken as $p_{1}$ and $T_{1}$ and it is not an ideal reservoir upstream. There is an EGR cooler between the exhaust manifold and the EGR valve. The pressure drop across the EGR cooler is small while the temperature drop is significant. From energy point of view, it is better to use the temperature of the EGR gas out of EGR cooler as $T_{1}$ instead of exhaust manifold temperature. However, the temperature of the EGR gas out of EGR cooler is not generally measured in production engines and it is necessary to use the exhaust temperature. All these considerations will introduce a further reduction in model accuracy. Nevertheless, the model sufficiently represents the physical parameters to encourage a validation and assessment of the accuracy. With validation information, the suitability of the application of the model for particular purposes can be assessed. For example, the control oriented model is allowed to have some model uncertainty.

With the simplified pressure ratio characteristic function $\phi$ and the replacement of $p_{T}$ with $p_{2}, p_{0}$ with $p_{1}$ and $T_{0}$ with $T_{1}$, the mass flow rate model in equation (8) can be rewritten as: 


$$
\dot{m}_{T}=\frac{A_{T} p_{1}}{\sqrt{R T_{1}}} \phi\left(\frac{p_{2}}{p_{1}}\right), \quad\left(\frac{p_{1}}{p_{2}}\right)_{\min }<\frac{p_{2}}{p_{1}}<1
$$

The minimum pressure ratio $\left(\frac{p_{1}}{p_{2}}\right)_{\min }$ will be different to the minimum pressure ratio $\left(\frac{p_{T}}{p_{0}}\right)_{\min }$. But they are reached at the same time when the flow across the throat starts to be choked.

Both the minimum pressure ratio $\left(\frac{p_{1}}{p_{2}}\right)_{\min }$ and $\phi\left(\frac{p_{2}}{p_{1}}\right)$ can be tuned using engine experimental test data. The tuned result of $\phi\left(\frac{p_{2}}{p_{1}}\right)$ can be stored in a polynomial regression model or simply a look up table.

Combining the discharge coefficient and the EGR valve open area together, an EGR valve characteristic function can be formed as in equation (11) to replace $A_{T}$ in equation (10).

$$
\dot{m}_{e g r}=\frac{A_{e g r m a x} f\left(\chi_{e g r}\right) p_{1}}{\sqrt{R T_{1}}} \phi\left(\frac{p_{2}}{p_{1}}\right), \quad\left(\frac{p_{1}}{p_{2}}\right)_{\min } \leq \frac{p_{2}}{p_{1}} \leq 1
$$

Where, $X_{\text {egr }}$ is the normalized EGR valve open position which is between 0 and 1 and $f\left(X_{e g r}\right)$ is the nonlinear EGR valve characteristic function. $A_{\text {egrmax }}$ is maximum EGR valve open area when $X_{\text {egr }}$ is 1 . The units for each variable in EGR flow rate model (equation 10) are: $\dot{m}_{\text {egr }}:[\mathrm{kg} / \mathrm{s}] ; A_{\text {egrmax }}:\left[\mathrm{m}^{2}\right] ; p_{1}$ and $p_{2}:[\mathrm{Pa}] ; T_{1}:[\mathrm{K}] ; R=287[\mathrm{~J} / \mathrm{kg} . \mathrm{K}]$ for EGR gas; $\theta$ and $\phi$ are without unit.

The maximum EGR valve open area $A_{\text {egrmax }}$ is calculated from EGR valve radius $r_{\text {egr }}$ :

$$
A_{\text {egrmax }}=\pi r_{e g r}^{2}
$$

Including the choked flow situation, the complete EGR flow rate model can be represented in the following set of equations:

$$
=\left\{\begin{array}{lc}
\frac{A_{\text {egrmax }} f\left(\chi_{\text {egr }}\right) p_{1}}{\sqrt{R T_{1}}} \phi(1), & \frac{p_{2}}{p_{1}}>1 \\
\frac{A_{\text {egrmax }} f\left(\chi_{\text {egr }}\right) p_{1}}{\sqrt{R T_{1}}} \phi\left(\frac{p_{2}}{p_{1}}\right), & \left(\frac{p_{1}}{p_{2}}\right)_{\min } \leq \frac{p_{2}}{p_{1}} \leq 1 \\
\frac{A_{\text {egrmax }} f\left(\chi_{\text {egr }}\right) p_{1}}{\sqrt{R T_{1}}} \phi\left(\left(\frac{p_{1}}{p_{2}}\right)_{\min }\right), & \left(\frac{p_{1}}{p_{2}}\right)_{\min }>\frac{p_{2}}{p_{1}}
\end{array}\right.
$$

When $\frac{p_{2}}{p_{1}}>1$, the direction of flow in the EGR path will be reversed (i.e. negative flow rate). However, the model makes the simplification that there is no such reverse flow (i.e. no flow) as this condition rarely occurs in practice in the experimental work where this model is deployed.

When implementing the EGR flow rate model on the engine, the exhaust pressure and exhaust temperature or the temperature of EGR gas out of EGR cooler could be chosen as $p_{1}$ and $T_{1}$ respectively for inputs to the model. Since the gas condition in the exhaust manifold is not as ideal as the assumption of a large reservoir, there will be a limit to the accuracy of the model. The tuning of this EGR flow rate model for two different engines in the following two sections provides an indication of the limits in model accuracy by means of the R-squared statistic.

\section{Tuning Model Parameters}

The parameters requiring tuning in the EGR mass flow rate model in equation (13) include the EGR valve radius $r_{e g r}$ (if it is not precisely known), the minimum pressure ratio $\left(\frac{p_{1}}{p_{2}}\right)_{\min }$, the EGR valve characteristic function $f\left(X_{\text {egr }}\right)$ and the pressure ratio characteristic function $\phi\left(\frac{p_{2}}{p_{1}}\right)$. If the EGR valve radius is not known, it can be assumed to be a reasonable value such $0.01 \mathrm{~m}$. Because the different value of $r_{\text {egr }}$ does not change the model accuracy. It only affect the scaling of the function $\left(\frac{p_{2}}{p_{1}}\right)$.

\section{Identify EGR Valve Characteristic Curve}

Referring back to equation (11), it can be seen that the tuning of the two nonlinear functions $f\left(X_{e g r}\right)$ and $\phi\left(\frac{p_{2}}{p_{1}}\right)$ is the most critical part to achieving a reliable EGR flow rate model. Rewriting equation (11):

$$
f\left(\chi_{\text {egr }}\right) \phi\left(\frac{p_{2}}{p_{1}}\right)=\frac{\dot{m}_{\text {egr }} \sqrt{R T_{1}}}{A_{\text {egrmax }} p_{1}}, \quad\left(\frac{p_{1}}{p_{2}}\right)_{\text {min }} \leq \frac{p_{2}}{p_{1}} \leq 1
$$

From equation (14), ideally if $\frac{p_{2}}{p_{1}}$ is kept constant, $\phi$ will not change, then the shape of right side value varying with EGR valve position, could be considered as the EGR valve characteristic curve.

Figure 9 presents a scatter plot of the pressure ratio $\left(\frac{p_{2}}{p_{1}}\right)$ of intake manifold pressure to exhaust pressure against engine speed for data captured from the C6.6 engine. This data consists of an EGR sweep test at 34 engine steady state operating points which covers the achievable engine operating speed and torque range. Five operating points are highlighted and marked in Figure 9 with their respective engine speed and torque operating conditions.

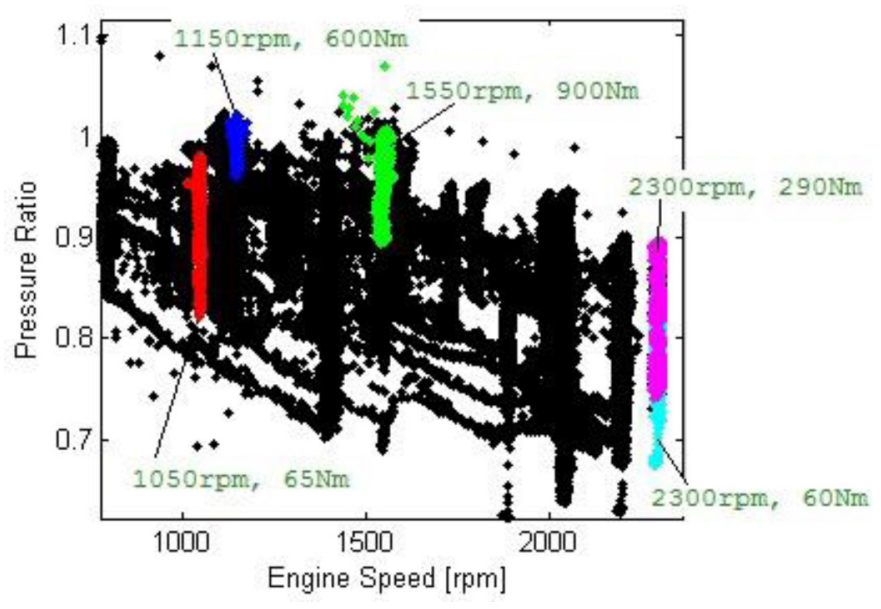

Figure 9. Pressure ratio vs engine speed for C6.6 engine

It can be seen from Figure 9 that pressure ratio drops when engine speed increases and the pressure ratio increases when engine load increases. The minimum variation of pressure ratio during a sweep of 
the EGR valve occurs at the low engine speed and high engine load condition. The vane position of the VGT was kept at a constant value of $50 \%$ for all EGR sweep tests. The exhaust pressure and exhaust temperature was used as $p_{1}$ and $T_{1}$ in this example so that the modelling results could be compared to these of the second example in which the temperature of EGR gas at the exit of EGR cooler was used as $T_{1}$.

Figure 10 shows the pressure ratio and measured EGR flow rate during the EGR valve sweep test at engine operating point 1050rpm, $600 \mathrm{Nm}$. No obvious variation of pressure ratio during EGR valve position change is observed. Since the EGR mass flow rate, exhaust pressure, exhaust temperature and maximum EGR valve open area A_egrmax are all known variables, the values of the right side of equation (14) were computed and plotted against EGR valve position. A two order polynomial regression model was developed and the model output was plotted together with the computed data, Figure 11.
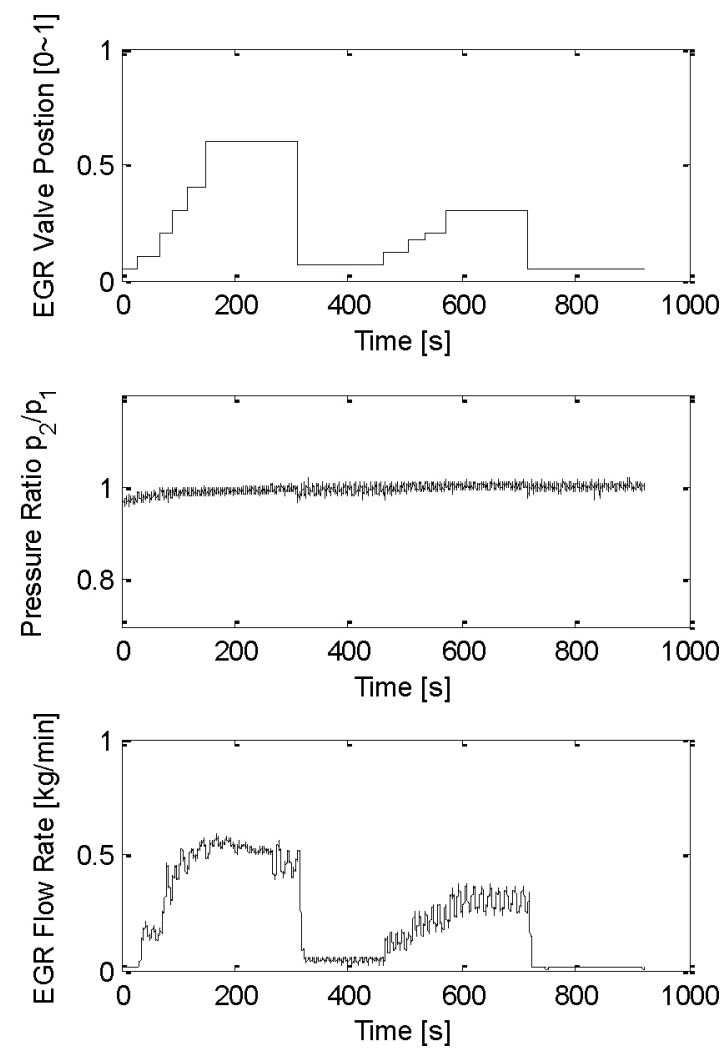

Figure 10. EGR valve position, pressure ratio and measured EGR flow mass flow rate during the EGR valve sweep test at engine operating point $1050 \mathrm{rpm}$ $600 \mathrm{Nm}$ for the C6.6 engine

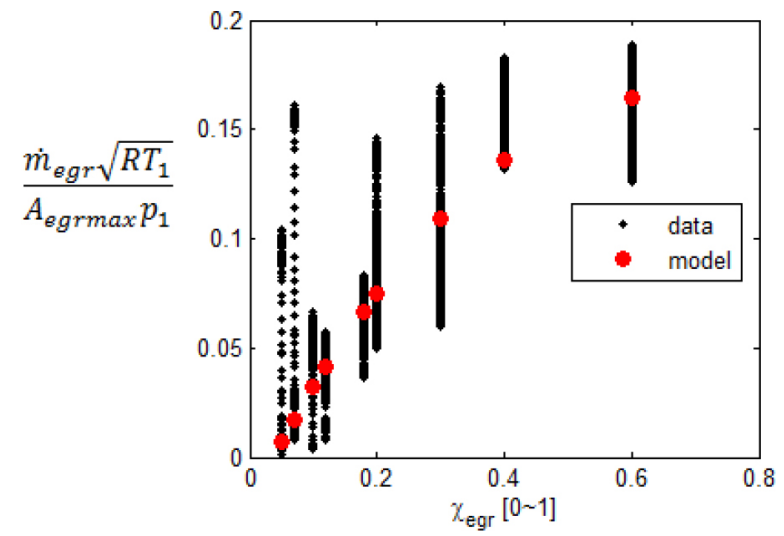

Figure 11. Computed right side value of equation (14) vs EGR valve position for the C6.6 engine
By normalizing the model curve and expanding it up to EGR valve fully open, the nonlinear EGR valve characteristic curve $f\left(X_{\text {egr }}\right)$ is shown in Figure 12.

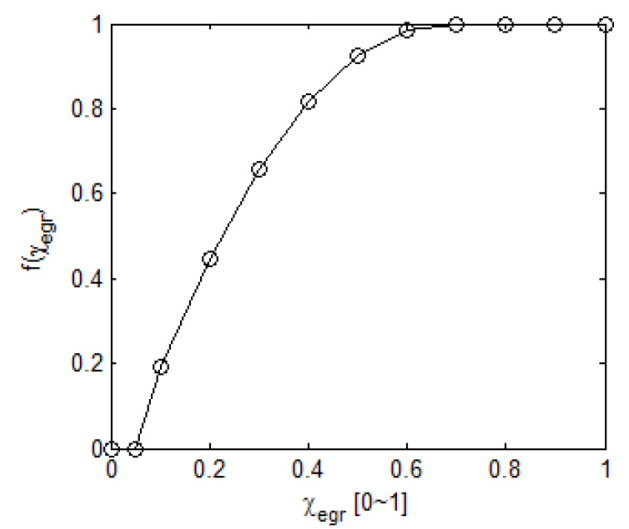

Figure 12. Normalized nonlinear EGR valve open characteristic curve

\section{Identify Minimum Pressure Ratio and Pressure Ratio Characteristic Curve}

The minimum pressure ratio $\left(\frac{p_{1}}{p_{2}}\right)_{\min }$ and pressure ratio characteristic function $\phi\left(\frac{p_{2}}{p_{1}}\right)$ are identified together. This process starts with the careful selection of engine operating points to minimize the engine test requirement whilst at the same time maximizing the achievable value range for pressure ratio. The results presented in Figure 9 indicate that at least two engine speed conditions should be selected to collect the test data for model tuning, one at low speed and the other at high speed. A combination of engine load conditions should be selected to ensure that the pressure ratio computed from the engine test data covers the most achievable range of the engine.

Figure 13 through to Figure 16 show the process to obtain an estimate of the $\phi$ value against pressure ratio $\frac{p_{2}}{p_{1}}$ for one engine operating point for the C6.6 engine. Firstly, the value of the product of two functions $f\left(\chi_{\text {egr }}\right) \phi\left(\frac{p_{2}}{p_{1}}\right)$ is computed using equation (14). Then a polynomial regression model of $f \phi$ varying with EGR valve position is developed, Figure 13.

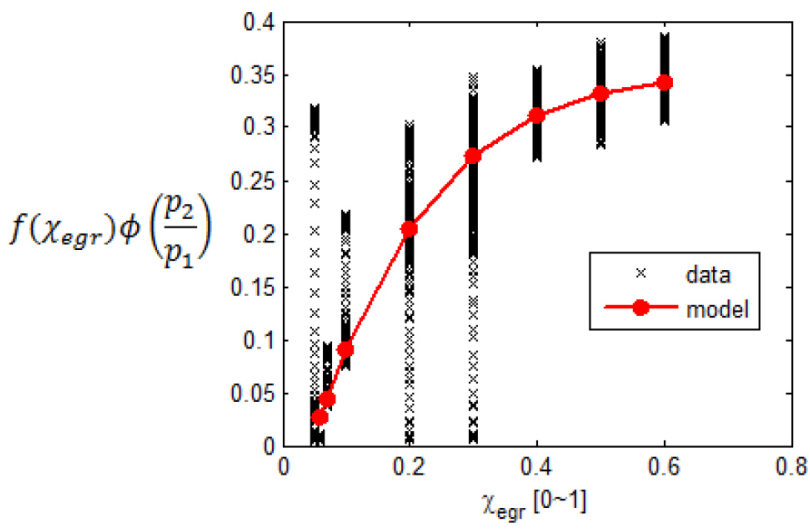

Figure 13. The determination of EGR valve function and pressure ratio function vs. EGR valve position from engine test data using equation (14) for the C6.6 engine 
The model output value for $f \phi$ is used in the next step which is to obtain the $\phi$ value by dividing $f \phi$ by $f\left(X_{\text {egr }}\right)$. The estimated $\phi$ relationship to EGR valve position is plotted in Figure 14.

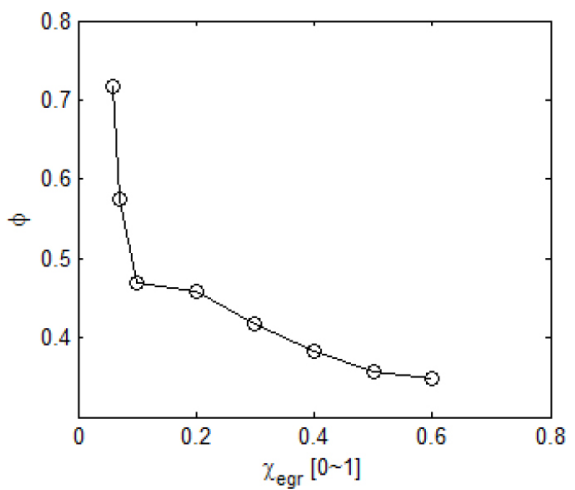

Figure 14. Estimated $\phi$ vs. EGR valve position from engine test data at operating point $1400 \mathrm{rpm}, 400 \mathrm{Nm}$ for the C6.6 engine

Thirdly, a polynomial regression model is developed for the relationship between pressure ratio and EGR valve position, Figure 15.

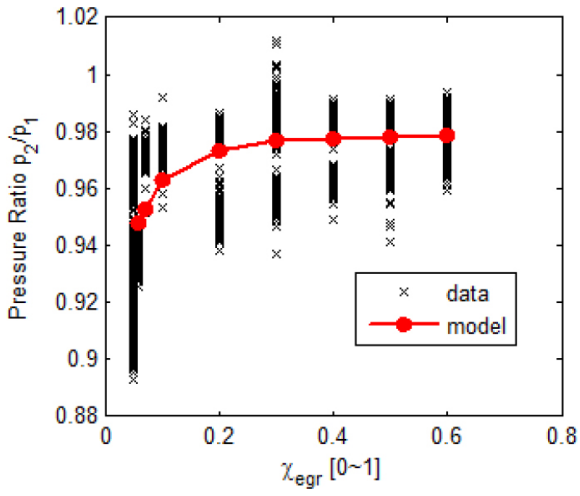

Figure 15. Pressure ratio vs. EGR valve position from engine test data at operating point $1400 \mathrm{rpm}, 400 \mathrm{Nm}$ for the C6.6 engine

The model output is then used to plot the relationship between $\phi$ and pressure ratio $\frac{p_{2}}{p_{1}}$, Figure 16 .

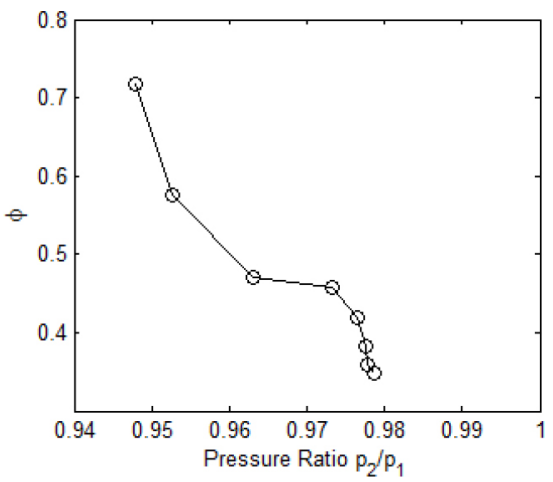

Figure 16. Estimated $\phi$ against pressure ratio from engine test data at engine operating point $1400 \mathrm{rpm}, 400 \mathrm{Nm}$ for the C6.6 engine

The method described in Figure 13 through Figure 16 has been used to calculate the estimated $\phi$ against pressure ratio for five further $\mathrm{C} 6.6$ engine test data sets. The results of these six data sets are summarised in Figure 17.

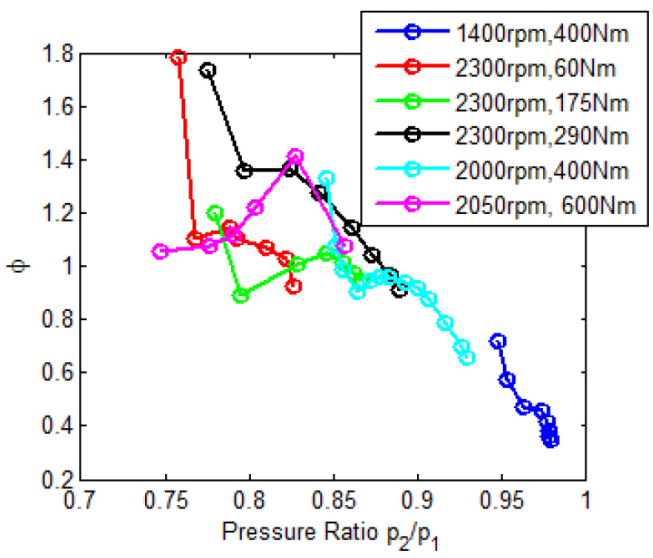

Figure 17. Estimated $\phi$ against the pressure ratio for six engine operating points for the C6.6 engine

Finally, the computed results of these six C6.6 engine test data sets provide the basis for the estimation of the pressure ratio characteristic curve by a second order polynomial regression modelling approach and this is shown in Figure 18.

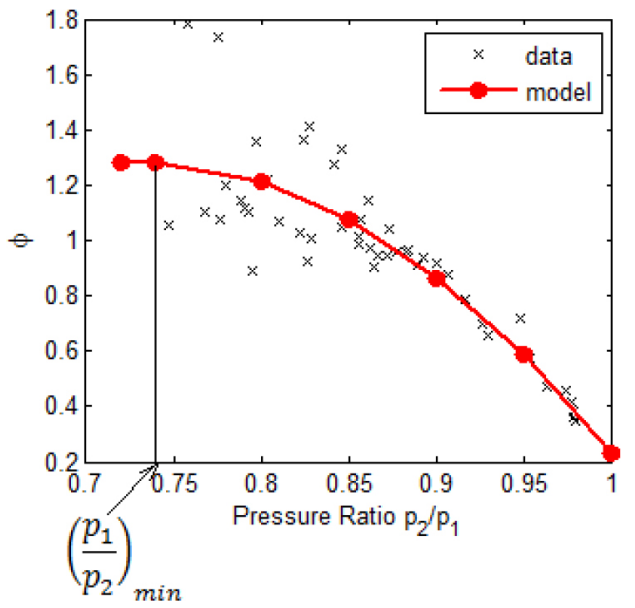

Figure 18. Identified pressure ratio characteristic function and the minimum pressure ratio for the C6.6 engine

From the regression curve in Figure 18 it is possible to estimate the minimum pressure ratio value which is $\sim 0.74$ for the C6.6 engine. This is the value of pressure ratio at which $\phi$ stops increasing and becomes flat in the decreasing direction of pressure ratio i.e. the regression model is asymptotic to a horizontal line representing the maximum value of $\phi$. Using more engine test data to identify the pressure ratio function will increase the total model accuracy.

Model accuracy is limited by the deviation of the real EGR flow environment from the ideal reservoir assumptions and being unable to measure pressure at the valve location. The example presented in Figure 13 through $\underline{18}$ for the C6.6 engine data demonstrates that less than six engine operating points can give a reasonably acceptable model accuracy. Of course, the relationship between $\phi$ and the pressure ratio $\frac{p_{2}}{p_{1}}$ can also be extracted from the engine test data without applying regression modelling method, however, an advantage of the regression modelling method is that it acts to filter out noise from the engine test data leading to a more robust identification of $\phi$. 
The validation results for the C6.6 engine are presented in Figure 19 and Figure 20. The R-squared value for the tuning data and validation data are 0.9140 and 0.8973 respectively.

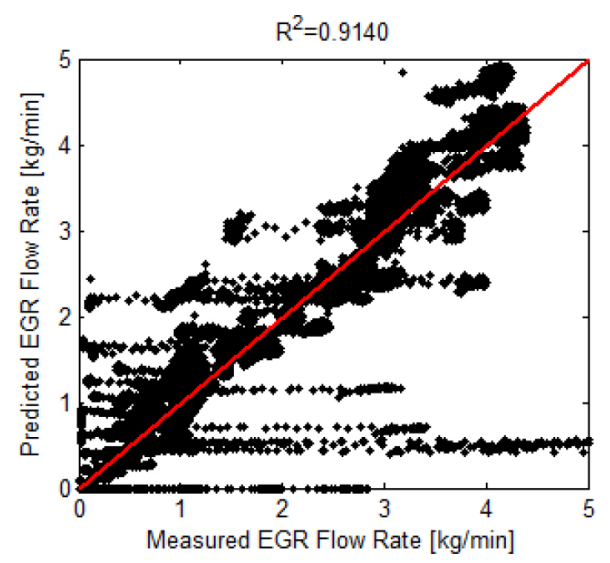

Figure 19. Model validation result using the data sets (total 6) for model parameters tuning (the red straight line denotes perfect model agreement)

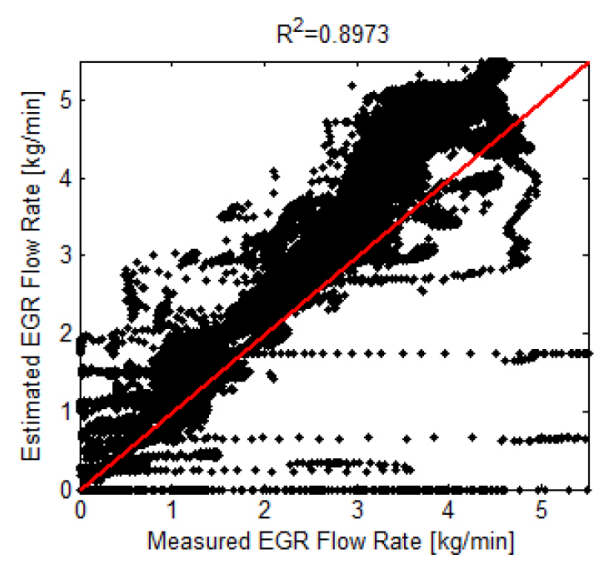

Figure 20. Model validation result using the data sets (total 7) that are not used in model parameters tuning (the red straight line denotes perfect model agreement)

The data sets that are not used in the tuning of the model parameters were collected from EGR sweep tests at engine steady state operating points that are different to those used in model tuning and this explains why there is a difference in the computed R-squared value. Both R-squared values are bigger than 0.89 which indicates that this EGR flow rate model is reliable enough for control purposes.

It should be noted that all captured data points from the tuning and validation tests are plotted in Figure 19 and Figure 20 to illustrate model fit for all measured data. As a result, groups of data points can be identified to run roughly parallel to the $\mathrm{x}$-axis in both Figure 19 and Figure 20. These represent brief spikes in the EGR flow rate measured by the Horiba emissions analyzer during a step change of the EGR valve position. This is because the EGR ratio is based on the measurement of the $\mathrm{CO}_{2}$ concentration of both the intake air and exhaust gas. During a transient, such as an EGR valve step change, there can be a time difference between the measured change in intake $\mathrm{CO}_{2}$ concentration and the measured change in exhaust $\mathrm{CO}_{2}$ concentration. These spikes in the estimated value are therefore not the true EGR flow rate, rather they are artifacts of the measurement technique.
The model validation results in Figure 19 and Figure 20 are representative of steady state engine conditions for the C6.6 engine. Validation results for the EGR flow model during engine transients are presented in the next section which describes the modelling results for the $\mathrm{C} 7.1$ engine.

The development process for the EGR mass flow rate model for a specific engine with the formulation in equation (13) can be summarized in the following steps:

\section{Step 1}

Carefully define the engine operating points for the engine EGR valve sweep tests ensuring a combination of different engine speed and load conditions are explored which maximize the achievable value range for pressure ratio. Perform the engine tests to collect the data for the model parameter tuning.

\section{Step 2}

Identify a single engine test data set where the pressure ratio does not vary much during the EGR valve sweep test. This usually happens at low engine speed and high load operating point, Figure 9. The EGR valve characteristic curve can be identified from this data set. Usually normalization is required.

\section{Step 3}

Compute the value of $f\left(\chi_{\text {egr }}\right) \phi\left(\frac{p_{2}}{p_{1}}\right)$ using equation (13) for each EGR sweep test data set. Applying the polynomial regression modelling method to find two relationships: $f \phi \sim \chi_{\text {egr }}$ and $\frac{p_{2}}{p_{1}} \sim \chi_{\text {egr }}$. Since $f\left(X_{\text {egr }}\right)$ was identified in Step 2, then the relationship $\phi \sim X_{\text {egr }}$ can be computed. Hence, the relationship $\phi \sim \frac{p_{2}}{p_{1}}$ for each EGR sweep test data set may be obtained.

\section{Step 4}

Combine together all $\phi \sim \frac{p_{2}}{p_{1}}$ that are computed in Step 3 for each engine data set and use the polynomial regression modelling method to find the smooth nonlinear pressure ratio curve for this specific engine that best fits the engine test data. The shape of this pressure ratio curve should be similar to that in Figure 18.

A diagram of the EGR flow rate model derived from steps 1 through 4 is depicted in Figure 21. This model has four inputs and one output. The tuning parameters include two nonlinear curves and one constant which is the minimum pressure ratio.

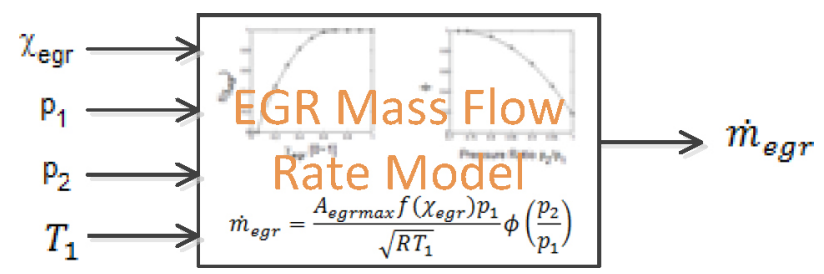

Figure 21. Diagram of an EGR flow rate model 


\section{Modelling Results for the C7.1 Engine}

The modelling techniques described in the proceeding section have been applied to the C7.1 engine. The identified normalized EGR valve characteristic curve and pressure ratio characteristic curve are plotted together with those of C6.6 engine in Figure 22 and Figure 23 respectively.

The two identified nonlinear curves of the C7.1 engine are both slightly different to those of the C6.6 engine, possibly because of the different $T_{1}$. For the C7.1 engine, the temperature of the EGR gas at the exit location of EGR cooler was used as $T_{1}$.

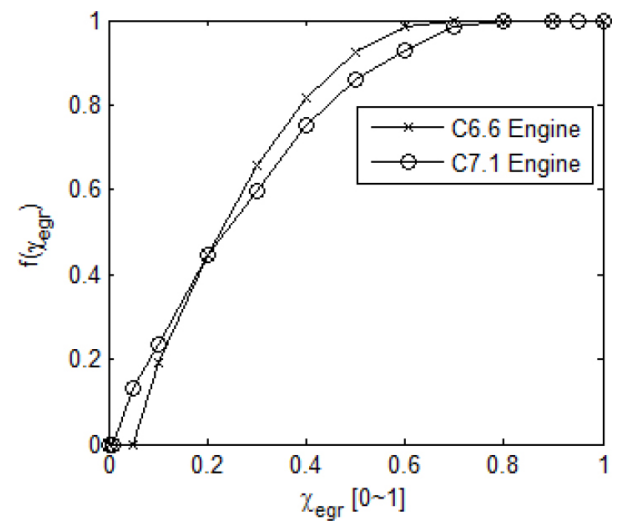

Figure 22. EGR valve open characteristic curves of C6.6 engine and C7.1 engine

From Figure 23 it is clear that the identified minimum pressure ratio at which the EGR valve pressure ratio characteristic curve asymptotes to the maximum value of $\phi$ was found to be different for the two engines. This is attributable to the different geometric features of the EGR valve designs and EGR path of the two engines.

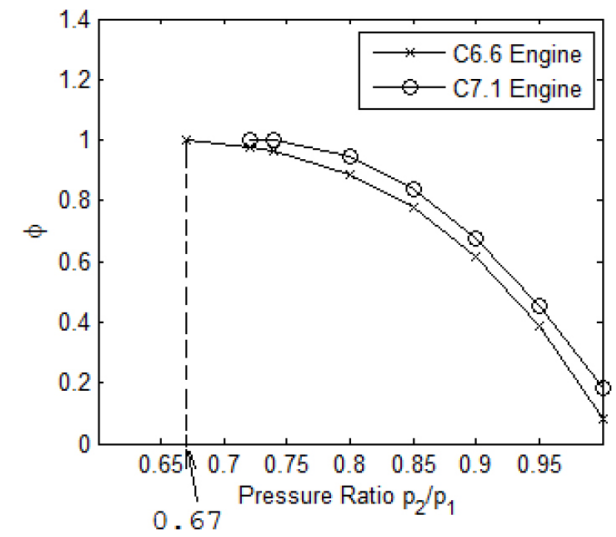

Figure 23. Normalized pressure ratio characteristic curves of C6.6 engine and C7.1 engine

Although the minimum pressure ratio are different, the asymptotic behavior of the characteristic curve at lower pressure ratio means the relative difference in normalized $\phi$ is small between these two engines at low pressure ratios. Therefore, it is feasible to combine the two pairs of curves into a single pair of curves and then simply adjust the value of EGR valve radius to tune the EGR flow rate model. This approach vastly reduces the model tuning process with reduced tuning time and cost but at the expense of some model accuracy. In this approach, the tuned EGR valve radius used in the model is likely not the actual valve radius; therefore it can be named as equivalent radius. This proposed simplification of the model tuning needs to be verified by assessing a broad range of engines and this is beyond the scope of the present work.

Figure 24 presents the model validation results for the $\mathrm{C} 7.1$ engine running at a constant $1800 \mathrm{rpm}$ with a sequence of step changes in engine load, VGT vane position and ETA torque demand. The EGR valve opening position was controlled using a non-production EGR mass flow closed loop controller with set-points designed to validate the performance of the EGR mass flow model over a broad range of movement of the EGR valve. The model EGR mas flow estimation was used as feedback. For the ETA, $>0 \%$ represents electrical motoring assist of the turbocharger and $<0 \%$ represents electrical generation (i.e. braking of the turbocharger). In this test the dynamometer is in torque control mode and the engine speed is maintained by the engine speed governor.

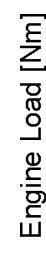
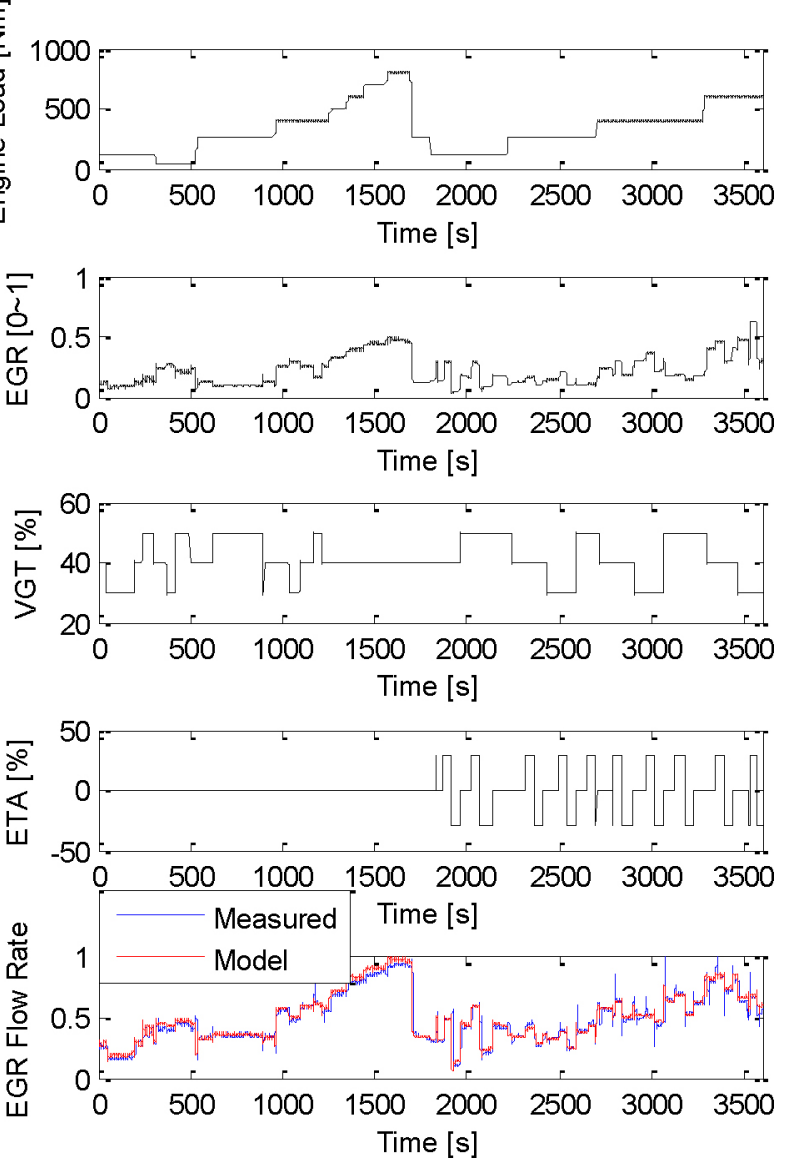

Figure 24. Model validation results for C7.1 engine under step change of engine load, VGT vane position and ETA torque with closed loop EGR valve control using model estimated EGR flow rate feedback

The EGR flow rate model uses the C7.1 engine EGR valve characteristic curves determined from engine test data, Figure 22 and Figure 23. The model was tuned at engine steady state operating points with the VGT vane position fixed at $50 \%$ and the ETA off.

The EGR flow rate measured by the Horiba analyzer and the model estimation have been normalized to the maximum EGR flow rate.

The EGR flow rate estimated from the EGR model follows the measured EGR flow rate well with a slight over estimation of EGR mass flow at very high engine load. Good accuracy is observed for 
different combinations of VGT, EGR valve and ETA motoring/ generating combinations over a large change in engine load. The demonstrated accuracy of the model for different ETA motoring and generating conditions is a particularly interesting finding and to the authors' knowledge has not been shown elsewhere. This indicates that the EGR flow rate model and tuning method investigated in this work can be applied in ETA equipped air-path systems.

Momentary spikes in the measured EGR mass flow in Figure 24 are the result of the Horiba analyzer exhaust and intake $\mathrm{CO} 2$ measurements not being time aligned during transient events, as was described in the previous section. Therefore, the step changes in VGT and ETA demand result in a brief period of unreliability in the EGR mas flow measurement until the system stabilizes. The model does not have this issue and is therefore more reliable than the measured EGR mass flow during step changes. This is an advantage of this EGR mass flow model for closed loop EGR mass flow control as shown here.

Figure 25 is a scatter plot of EGR flow rate estimated from the EGR flow rate model against measured EGR flowrate from the C7.1 engine test shown in Figure 24. The R-squared value is 0.9339 which is slightly better than for the C6.6 engine and shows that this EGR flow rate model has reasonably good model accuracy for the C7.1 engine. This result shows that good model accuracy can be achieved even when the model is tuned to data which does not include changes in VGT position or ETA electrical motoring assist/generating. This strengthens the earlier proposal that a generalized pair of EGR valve opening characteristics curves can be applied with tuning of the EGR valve equivalent radius to simplify the model tuning process for the two engines investigated in this study.

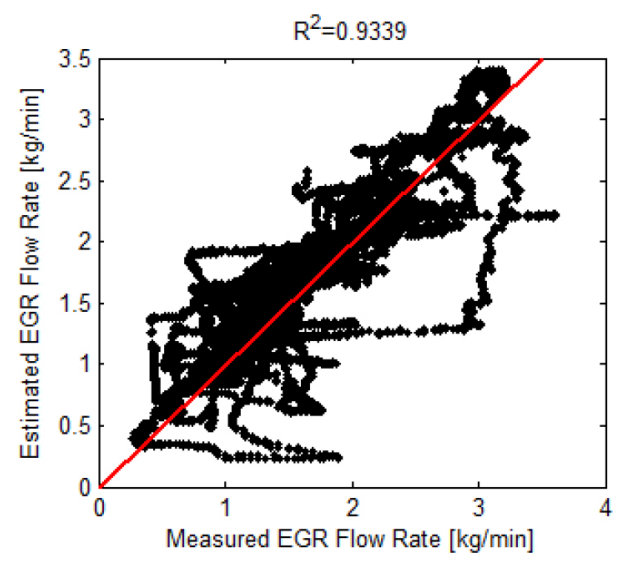

Figure 25. A scatter plot of measured EGR flow rate and EGR Model estimated flow rate for the C7.1 engine (the same test data plotted in Figure $\underline{24}$ ); (the red straight line denotes perfect model agreement)

This can be understood from the EGR flow model discussed in this paper being based on the geometric features of EGR valve and the EGR path, not based on engine operating conditions. The main requirement is therefore that the engine test data for pressure ratio curve tuning covers the range from minimum pressure ratio to a value close to 1 . The method used in this paper to meet this requirement involved careful selection of engine speed and load operating conditions. It is expected that a similar or improved model accuracy could be achieved if the tuning data also includes different VGT vane position and ETA input settings. The investigation of this is beyond the scope of this work.
This tuned and validated EGR flow rate model for the C7.1 engine has been utilized to demonstrate a decoupled $3 \mathrm{I} 3 \mathrm{O}$ air path control system in which the model estimated EGR flow rate was closed-loop feedback-controlled together with intake manifold pressure and exhaust pressure using VGT vane position, EGR valve position and ETA electrical machine torque. The set-points for these three controlled variables were determined online via an Equivalent Consumption Minimization Strategy (ECMS) algorithm. This work will be presented in future publications by the authors.

\section{Summary/Conclusions}

A detailed discussion about the formation and intrinsic model accuracy reduction of a commonly used EGR flow rate model was presented in this paper. The intrinsic model accuracy reduction is caused by two main factors. One is that the real engine environment for EGR path upstream and downstream is not a steady reservoir as it is assumed in the model formation. The other is using the manifold pressure to replace the pressure at the valve location in computing the pressure ratio, as the pressure at the valve location is not available.

A practical model parameter tuning process was proposed and two examples of model tuning were carried out on test data from two diesel engines. One diesel engine is a Cat C6.6 equipped with HP EGR and VGT. The other diesel engine is a Cat C7.1 equipped with HP EGR, VGT and an ETA. There are two key nonlinear functions or curves that need to be tuned in the EGR flow model which are the EGR valve open characteristic curve and the pressure ratio characteristic curve. It was found that it was feasible to identify the EGR valve open characteristic curve with a single sweep of EGR valve position at low engine speed and a high load steady state operating point. Several EGR sweep tests at carefully selected engine steady state operating points could then be used to identify the pressure ratio characteristic curve. It was found that the choice of other air path control variables such as VGT vane position and ETA torque demand, were not so important for achieving a well-tuned EGR flow rate model.

Though there are two intrinsic model accuracy reduction problems, the validation results show that this EGR flow rate model has good model accuracy for the two engines it was applied to in this study. The usage of the EGR gas temperature at the exit of EGR cooler was found to give slightly better model accuracy. The use of engine steady state test data for model parameter tuning was found not to limit the model's reliability during engine transient operation.

The EGR mass flow rate model discussed here is easy to tune and has good model accuracy. It uses the measured variables that are available in most production engines e.g. exhaust pressure, exhaust temperature and intake manifold pressure. It has been shown to be reliable on an engine air path system that has new device such as ETA $[\underline{31}, \underline{32}]$ in combination with VGT and EGR. It provides a reliable estimation of EGR mass flow rate that enables the MIMO air path closed-loop control system to be included in the EGR flow rate control. It is also suitable for incorporation into a mean value engine model (MVEM) for global optimization of engine fuel consumption and emissions. 


\section{References}

1. Zheng M., Reader G. T. and Hawley J. G., "Diesel Engine Exhaust Gas Recirculation-A Review on Advanced and Novel Concepts", Energy Conversion and Management 45 (2004) 833900 .

2. Ammann, M., Fekete, N., Guzzella, L., and Glattfelder, A., "Model-Based Control of the VGT and EGR in a Turbocharged Common-Rail Diesel Engine: Theory and Passenger Car Implementation," SAE Technical Paper 2003-01-0357, 2003, doi:10.4271/2003-01-0357.

3. Friedrich I., Liu C. and Oehlerking D., "Coordinated EGR-Rate Model-Based Controls of Turbocharged Diesel Engine via an Intake Throttle and an EGR Valve", Proceedings of Vehicle Power and Propulsion Conference, 2009, page 340-347.

4. Katrasnik T., Rodman S., Trenc F., Hribernik A. and Medica V., "Improvement of the Dynamic Characteristic of an Automotive Engine by a Turbocharger Assisted by an Electric Motor", Transactions of ASME, Vol. 125, April 2003, page 590-595.

5. Hopmann, U. and Algrain, M., "Diesel Engine Electric Turbo Compound Technology," SAE Technical Paper 2003-01-2294, 2003, doi:10.4271/2003-01-2294.

6. Yan F., Wang J., "Control of Diesel Engine Dual-Loop EGR Air-Path Systems by a Singular Perturbation Method", Control Engineering Practice, Volume 21, Issue 7, July 2013, Page 981988.

7. Guzzella L., Amstutz A., "Control of Diesel Engines”, IEEE Journal of Control Systems, Volume 18, Issue 5, August 2002.

8. Chauvin J., Corder G. and Petit N., "Transient Control of a Diesel Engine Airpath", Proceedings of the 2007 American Control Conference, New York City, USA, July 11-13, 2007.

9. BakerR. C., "An Introductory Guide to Flow Measurement", Professional Engineering Publishing Limited, 2002.

10. Nakamura H., Asano I., Adachi M. and Senda J., "Analysis of Pulsating Flow Measurement of Engine Exhaust by a Pitot Tube Flowmeter", International Journal of Engine Research, 2005.

11. Brahma, I., Schmidt, J., Confair, R., Kurtz, J. et al., "An Investigation into the Accuracy of Orifice Based Flow Estimates for Pulsating Compressible Flows," SAE Int. J. Engines 7(1):313-322, 2014, doi:10.4271/2014-01-1154.

12. Reuter, W., Lösing, K., and Golden, J., "An Improved AntiPulsation Mass Airflow Sensor," SAE Technical Paper 2001-010985, 2001, doi:10.4271/2001-01-0985.

13. Hall, M. and Zuzek, P., "Fiber Optic Sensor for Time-Resolved Measurements of Exhaust Gas Recirculation in Engines," SAE Technical Paper 2000-01-2865, 2000, doi:10.4271/2000-01$\underline{2865}$.

14. Sutela, C., Collings, N., and Hands, T., "Real Time CO2 Measurement to Determine Transient Intake Gas Composition under EGR Conditions," SAE Technical Paper 2000-01-2953, 2000, doi:10.4271/2000-01-2953.

15. Griffin, J., Ganseman, C., Baerts, C., Burkholder, N. et al., "Cooled EGR Rate Measurement with a Thermal Anemometer for EPA02 Heavy Duty Diesel Engine Emission Control," SAE Technical Paper 2003-01-0263, 2003, doi:10.4271/2003-01$\underline{0263}$.
16. Miklánek, L., Klír, V., Emrich, M., and Pohořelský, L., "Thermal Balance Method for EGR Rate Determination Usable for Real Engine with Uncooled EGR System," SAE Technical Paper 2009-01-1114, 2009, doi:10.4271/2009-01-1114.

17. Lee, S., Lee, J., Lee, S., Kim, D. et al., "Study on Reduction of Diesel Engine Out Emission through Closed Loop Control based on the In-Cylinder Pressure with EGR Model," SAE Technical Paper 2013-01-0322, 2013, doi:10.4271/2013-010322.

18. Alfieri E., Amstutz A., Guzzella L., "Gain-Schedule ModelBased Feedback Control of the Air/Fuel Ratio in Diesel Engines", Control Engineering Practice, Volume 17, Issue 12, December 2009, Pages 1417-1425.

19. Jung M. and Glover K., "Calibratable Linear Parameter-Varying Control of a Turbocharged Diesel Engine”, IEEE Transactions on Control System Technology, Volume 14, Issue 1, 2006, Pages: 45-62.

20. Wang J., "Hybrid Robust Air-Path Control for Diesel Engines Operating Converntional and Low Temperature Combustion Modes", IEEE Transactions on Control Systems Technology, Volume 16, Issue 6, 2008, Pages 1138-1151.

21. Jankovic M., Jankovic M. and Kolmanovsky I., "Constructive Lyapunov Control Design for Turbocharged Diesel Engines", IEEE Transactions on Control System Technology, Volume 8, No. 2, March 2000.

22. Nyberg M. and Stutte T., "Model Based Diagnosis of the Air Path of an Automotive Diesel engine", Control Engineering Practice, Volume 12, Issue 5, May 2004, Pages 513-525.

23. Catania, A., Finesso, R., and Spessa, E., "Real-Time Calculation of EGR Rate and Intake Charge Oxygen Concentration for Misfire Detection in Diesel Engines," SAE Technical Paper 2011-24-0149, 2011, doi:10.4271/2011-24-0149.

24. Brahma, I., Ofili, O., Campbell, M., Chiang, H. et al., "An Investigation into the Use of the EGR Cooler Pressure Drop to Measure EGR Flow Rate," SAE Technical Paper 2015-01-1639, 2015, doi:10.4271/2015-01-1639.

25. Wahlstrom J. and Eriksson L., "Modelling Diesel Engines with a Vairable-Geometry Turbocharger and Exhaust Gas Recirculation by Optimization of Model Parameters for Capturing Nonlinear System Dynamics", Journal of Automobile Engineering, Volume 225, Part D.

26. Galindo, J., Lujan, J., Climent, H., Guardiola, C. et al., "A New Model for Matching Advanced Boosting Systems to Automotive Diesel Engines," SAE Int. J. Engines 7(1):131-144, 2014, doi:10.4271/2014-01-1078.

27. Nakamura, T., Suzuki, Y., Kusaka, J., Ogawa, M. et al., "Modeling of Diesel Engine Components for Model-Based Control (First Report): The construction and validation of a model of the Air Intake System," SAE Technical Paper 2011-012066, 2011, doi:10.4271/2011-01-2066.

28. Azzoni, P., Minelli, G., Moro, D., and Serra, G., "A Model for EGR Mass Flow Rate Estimation," SAE Technical Paper 970030, 1997, doi:10.4271/970030.

29. Winward, E., Deng, J., and Stobart, R., "Innovations In Experimental Techniques For The Development of Fuel Path Control In Diesel Engines," SAE Int. J. Fuels Lubr. 3(1):594613, 2010, doi:10.4271/2010-01-1132. 
30. Heywood, "Internal Combustion Engine Fundamentals", McGraw-Hill, New York, 1988.

31. Winward E., Rutledge J., Carter J., Costall A., Stobart R., Zhao D. and Yang Z., "Performance testing of an electrically assisted turbocharger on a heavy duty diesel engine", To be Presented at the IMechE 12th International Conference on Turbochargers and Turbocharging, 17-18 May 2016.

32. WatkinsS. J., Winward E., "Modelling and control optimisation of an ultra-high-speed switched reluctance machine", To be presented at the 8th IET International Conference on Power Electronics, Machines and Drives. 19-21 April 2016.

\section{Contact Information}

Zhijia Yang

z.yang2@lboro.ac.uk

\section{Acknowledgments}

The authors would like to gratefully acknowledge the UK Engineering and Physical Sciences Research Council (EPSRC) for funding this research work under Grant Number: EP/K026658/1. The authors would also like to gratefully acknowledge the UK Engineering and Physical Sciences Research Council (EPSRC) for funding this research work under Grant Number: EP/K026658/1. The authors would also like to thank Graham Smith, Iain Harber, Dominic Mckean, Drew Mason and Steve Horner of the Loughborough University Powertrain Laboratory for their support to the engine experimental setup and throughout the engine testing.

\section{Definitions/Abbreviations}

CAD - Crank Angle Degree.

DI Drivers - Diesel Injector Driver Modules.

ETA - Electric Turbo Assist.

ETC - Electric Turbo Compound

ECM - Engine Control Module

EGR - Exhaust Gas Recirculation

FPGA - Field-Programmable Gate Array

HP - High Pressure

LP - Low Pressure

NI - National Instruments ${ }^{\mathrm{TM}}$

RT - Real Time

SR - Switched Reluctance

3I3O - Three-Input-Three-Output

TEG - Thermoelectric Generator

VGT - Variable Geometry Turbocharger

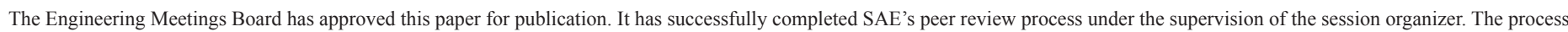
requires a minimum of three (3) reviews by industry experts.

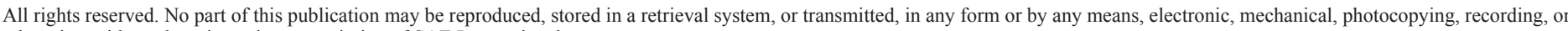
otherwise, without the prior written permission of SAE International.

Positions and opinions advanced in this paper are those of the author(s) and not necessarily those of SAE International. The author is solely responsible for the content of the paper.

ISSN 0148-7191

http://papers.sae.org/2016-01-0550 